\title{
VALOR NUTRITIVO DO ESTILOSANTES MINEIRÃO EM FUNÇÃO DA CORREÇÃO DO SOLO ${ }^{1}$
}

\author{
Jalison Lopes², Antônio Ricardo Evangelista 3 , Caio Augustus Fortes ${ }^{3}$, \\ José Cardoso Pinto ${ }^{3}$, Adriano Peixoto de Bastos Freire ${ }^{3}$, Ronan Magalhães de Souza ${ }^{4}$
}

\section{ABSTRACT \\ NUTRITIONAL EFFICIENCY OF Stylosanthes guianensis cv. Mineirão ACCORDING TO SOIL CORRECTION}

The main expectation for using leguminous plants in pastures is improving animal production and reducing production costs. This research was carried out in a greenhouse, in order to evaluate the effect of two soil acidity correctives and $\mathrm{P}$ rates on $\mathrm{P}, \mathrm{Ca}, \mathrm{Mg}, \mathrm{Si}$, raw protein (RP), neutral detergent fiber (NDF), acid detergent fiber (ADF), and in vitro dry matter digestibility (IVDMD) contents of Stylosanthes guianensis cv. Mineirão. A randomized blocks design was used in a $5 \times 2$ factorial arrangement, with five $P$ rates $\left(50 \mathrm{mg} \mathrm{dm}^{-3}, 100 \mathrm{mg} \mathrm{dm}^{-3}\right.$, $200 \mathrm{mg} \mathrm{dm}^{-3}, 400 \mathrm{mg} \mathrm{dm}^{-3}$, and $800 \mathrm{mg} \mathrm{dm}^{-3}$ of soil) and two soil correctives (lime and $\mathrm{Ca}$ and $\mathrm{Mg}$ silicate), with three replications. Both lime and silicate applications, previously to the phosphate fertilization, assured $\mathrm{P}, \mathrm{Mg}, \mathrm{Ca}, \mathrm{RP}, \mathrm{NDF}$, and $\mathrm{ADF}$ contents, in plants of Mineirão, compatible with good performances of grazing animals. The increase in the silicon content in Mineirão, resulting from silicate application, did not reduce the IVDMD. The substitution of lime by $\mathrm{Ca}$ and $\mathrm{Mg}$ silicate did not affect the nutritional value of the Mineirão subjected to phosphorus rates.

KEY-WORDS: Stylosanthes guianensis (Aubl.) Sw.; phosphate fertilization; lime and silicate application.

\section{INTRODUÇÃO}

A principal expectativa no uso de leguminosas em pastagens é a melhoria da produção animal e a redução dos custos de produção, quando comparados a gramíneas submetidas exclusivamente à adubação com nitrogênio mineral. Este benefício deve-se ao efeito direto da leguminosa, que melhora e diversifica a dieta do animal, e ao aumento da produção da gramínea, pelo maior aporte de nitrogênio $(\mathrm{N})$ no sistema, proporcionado pela fixação de $\mathrm{N}$ atmosférico (Pereira 2002).

\section{RESUMO}

A principal expectativa no uso de leguminosas em pastagens é a melhoria da produção animal e redução dos custos de produção. O presente experimento foi conduzido em casa-de-vegetação, com o objetivo de avaliar os efeitos do uso de dois corretivos de acidez do solo e doses de fósforo sobre os teores de $\mathrm{P}, \mathrm{Ca}, \mathrm{Mg}$, Si, proteína bruta (PB), fibra em detergente neutro (FDN), fibra em detergente ácido (FDA) e digestibilidade in vitro da matéria seca (DIVMS) do Stylosanthes guianensis cv. Mineirão. O delineamento experimental foi em blocos casualizados, com três repetições, com os tratamentos dispostos em esquema fatorial $5 \times 2$, com cinco doses de $\mathrm{P}\left(50 \mathrm{mg} \mathrm{dm}^{-3}\right.$, $100 \mathrm{mg} \mathrm{dm}^{-3}, 200 \mathrm{mg} \mathrm{dm}^{-3}, 400 \mathrm{mg} \mathrm{dm}^{-3}$ e $800 \mathrm{mg} \mathrm{dm}^{-3}$ de solo) e dois corretivos (calcário dolomítico e silicato de $\mathrm{Ca}$ e $\mathrm{Mg}$ ). Tanto a calagem como a silicatagem, previamente à fosfatagem, foram capazes de garantir teores de $\mathrm{P}, \mathrm{Mg}, \mathrm{Ca}, \mathrm{PB}, \mathrm{FDN}$ e FDA compatíveis, em plantas de estilosantes Mineirão, com bons desempenhos de animais em pastejo. O aumento do teor de silício no estilosantes Mineirão, decorrente da silicatagem, não reduziu a DIVMS. A substituição do calcário por silicato de $\mathrm{Ca}$ e Mg não prejudicou o valor nutritivo do estilosantes Mineirão submetido a doses de fósforo.

PALAVRAS-CHAVE: Stylosanthes guianensis (Aubl.) Sw.; fosfatagem; calagem; silicatagem.

Para um mesmo estádio de desenvolvimento e condição de cultivo, as leguminosas tropicais apresentam, em geral, maior proporção de proteína bruta (PB), menor proporção de parede celular e digestibilidade da matéria seca semelhante ou maior que a observada em gramíneas tropicais (Barcellos et al. 2008).

Vale ressaltar que o sucesso no estabelecimento, nodulação e fixação de $\mathrm{N}_{2}$ atmosférico, por leguminosas forrageiras, depende da adequada nutrição fosfatada (Gibson 1976). Como o custo unitário de

1. Trabalho recebido em jan./2011 e aceito para publicação em mar./2012 ( $\mathrm{n}^{\circ}$ registro: PAT 13039).

2. Universidade Federal de Roraima, Centro de Ciências Agrárias, Boa Vista, RR, Brasil. E-mail: jalisonufla@gmail.com.

3. Universidade Federal de Lavras, Departamento de Zootecnia, Lavras, MG, Brasil.E-mails: aricardo@dzo.ufla.br, caioufla@yahoo.com.br, josecard@dzo.ufla.br, peixotobastos1@yahoo.com.br.

4. Centro Universitário de Patos de Minas, Faculdade de Engenharia e Ciências Agrárias, Departamento de Zootecnia, Patos de Minas, MG, Brasil.E-mail: ronan@unipam.edu.br. 
fertilizantes fosfatados é relativamente alto, torna-se fundamental o desenvolvimento de tecnologias alternativas, que melhorem o aproveitamento do fósforo (P), nos solos brasileiros (Santos et al. 2002). A correção da acidez do solo com silicatos pode aumentar a eficiência da adubação fosfatada, pelo fato de o ânion $\mathrm{H}_{3} \mathrm{SiO}_{4}^{-}$liberado por este corretivo concorrer pelo mesmo sítio de adsorção que o ânion fosfato $\left(\mathrm{H}_{2} \mathrm{PO}_{4}^{-}\right)$, contribuindo, assim, para reduzir seu grau de fixação ao solo (Leite 1997).

A correção da acidez do solo, por meio do uso de silicato de cálcio $(\mathrm{Ca})$ e magnésio $(\mathrm{Mg})$, associada à adubação fosfatada, aumenta a eficiência de utilização dos macronutrientes fósforo $(\mathrm{P})$, nitrogênio $(\mathrm{N})$, cálcio $(\mathrm{Ca})$ e magnésio $(\mathrm{Mg})$ e do micronutriente zinco (Zn), pelo Stylosanthes guianensis cv. Mineirão (Lopes et al. 2010). No entanto, como o silicato de $\mathrm{Ca}$ e Mg também é fonte de silício ( $\mathrm{Si}$ ), e um dos locais de deposição deste elemento na planta é a parede celular, torna-se importante avaliar os possíveis efeitos do uso deste corretivo alternativo sobre a composição nutricional da leguminosa citada.

Desta forma, objetivou-se, com este trabalho, avaliar os efeitos do uso de dois corretivos de acidez do solo e doses de fósforo sobre os teores de $\mathrm{P}, \mathrm{Ca}$, $\mathrm{Mg}, \mathrm{Si}$, proteína bruta $(\mathrm{PB})$, fibra insolúvel em detergente neutro (FDN), fibra insolúvel em detergente ácido (FDA) e digestibilidade in vitro da matéria seca (DIVMS) do Stylosanthes guianensis cv. Mineirão.

\section{MATERIAL E MÉTODOS}

O experimento foi conduzido em casa-de-vegetação do Departamento de Ciência do Solo da Universidade Federal de Lavras (MG), de agosto de 2006 a março de 2007. Foi utilizado solo classificado como Latossolo Vermelho distroférrico (LVdf) (Embrapa 2006), de textura muito argilosa (70\% de argila), coletado em área de pastagem, à profundidade de $0-0,20 \mathrm{~m}$. Em seguida à coleta, o solo foi seco ao ar e passado em peneira com malha de 5,0 $\mathrm{mm}$. Após a secagem do solo, foi retirada uma amostra, a qual foi destinada às análises químicas e físicas.

$\mathrm{O}$ delineamento experimental utilizado foi em blocos casualizados, com três repetições, sendo os tratamentos dispostos em esquema fatorial $5 \times 2$, constituídos por cinco doses de $\mathrm{P}\left(50 \mathrm{mg} \mathrm{dm}^{-3}\right.$, $100 \mathrm{mg} \mathrm{dm}^{-3}, 200 \mathrm{mg} \mathrm{dm}^{-3}, 400 \mathrm{mg} \mathrm{dm}^{-3} \mathrm{e} 800 \mathrm{mg} \mathrm{dm}^{-3}$ de solo) e dois corretivos (calcário dolomítico e silicato de $\mathrm{Ca}$ e $\mathrm{Mg}$ ).
Antes do plantio, realizou-se a correção da acidez do solo com calcário dolomítico $(99,02 \%$ de PRNT, $36 \%$ de $\mathrm{CaO}$ e $9,0 \%$ de $\mathrm{MgO}$ ) e silicato de $\mathrm{Ca}$ e $\mathrm{Mg}(53 \%$ de PRNT, $36 \%$ de $\mathrm{CaO}$ e $14 \%$ de $\mathrm{MgO})$. A dose aplicada foi calculada pelo método da saturação de bases, visando a elevar a saturação por bases (V) de $44 \%$ para $60 \%$. Decorrida a aplicação dos corretivos, o solo permaneceu incubado por 165 dias. Este período de incubação foi utilizado para garantir que a reação do silicato com o solo fosse completa, em virtude do baixo poder relativo de neutralização total apresentado por este corretivo, conforme recomendado por Fortes et al. (2008).

O solo foi acondicionado em vasos plásticos sem furos, com capacidade para 4,0 $\mathrm{dm}^{3}(4,5 \mathrm{~kg}$ de solo), que receberam as cinco doses de $\mathrm{P}\left(50 \mathrm{mg} \mathrm{dm}^{-3}\right.$, $100 \mathrm{mg} \mathrm{dm}^{-3}, 200 \mathrm{mg} \mathrm{dm}^{-3}, 400 \mathrm{mg} \mathrm{dm}^{-3} \mathrm{e} 800 \mathrm{mg} \mathrm{dm}^{-3}$ de solo), na forma de ácido orthofosfórico $\left(\mathrm{H}_{3} \mathrm{PO}_{4}\right)$, e uma adubação básica de plantio, que constou de $120 \mathrm{mg} \mathrm{dm}^{-3}$ de potássio $(\mathrm{K})$, aplicado na forma de $\mathrm{K}_{2} \mathrm{SO}_{4}$ dos micronutrientes $\mathrm{Zn}\left(1,59 \mathrm{mg} \mathrm{dm}^{-3}\right)$, $\mathrm{B}\left(1,57 \mathrm{mg} \mathrm{dm}^{-3}\right), \mathrm{Cu}\left(0,33 \mathrm{mg} \mathrm{dm}^{-3}\right), \mathrm{Mn}\left(0,84 \mathrm{mg} \mathrm{dm}^{-3}\right)$, Mo $\left(0,15 \mathrm{mg} \mathrm{dm}^{-3}\right)$ e Co $\left(0,01 \mathrm{mg} \mathrm{dm}^{-3}\right)$, aplicados, respectivamente, nas formas de $\mathrm{ZnSO}_{4}, \mathrm{H}_{3} \mathrm{BO}_{3}$, $\mathrm{CuSO}_{4}, \mathrm{MnSO}_{4},\left(\mathrm{NH}_{4}\right)_{6}-\mathrm{Mo}_{7} \mathrm{O}_{24}$ e $\mathrm{CoCl}_{2}$. Após a aplicação dos nutrientes, foram retiradas amostras de solo de cada tratamento, para caracterizá-las por meio de análise química (Tabela 1).

A semeadura da leguminosa foi efetuada utilizando-se 20 sementes por vaso. O desbaste foi realizado 15 dias após a emergência, deixando-se cinco plantas por vaso. A umidade do solo foi ajustada para atingir $60 \%$ do volume total de poros e assim mantida por meio de pesagens periódicas, durante todo o experimento (Lopes et al. 2011). A duração do período experimental foi de 68 dias, contados a partir da semeadura. O corte da parte aérea das plantas foi realizado a $5,0 \mathrm{~cm}$ do solo, ao final do período experimental. Posteriormente, foi retirado o solo de cada vaso e as raízes separadas por lavagem em água corrente, utilizando-se peneira de $0,5 \mathrm{~mm}$ de malha. Todo o material coletado (parte aérea mais sistema radicular) foi seco em estufa com circulação forçada de ar, a $55^{\circ} \mathrm{C}$, por 72 horas, e depois pesado e triturado em moinho tipo Willey.

Os teores de $\mathrm{P}, \mathrm{Ca}$ e $\mathrm{Mg}$ da parte aérea do estilosantes Mineirão foram determinados conforme metodologia descrita por Sarruge \& Haag (1974). A digestão empregada foi a nitroperclórica e as leituras nos extratos, para os teores de $\mathrm{P}$, foram obtidas por 
Tabela 1. Caracterização química do solo, após incubação com silicato ou calcário e aplicação de fósforo (Lavras, MG, 2007).

\begin{tabular}{|c|c|c|c|c|c|c|c|c|c|c|}
\hline \multirow{4}{*}{ Atributos } & \multicolumn{10}{|c|}{ Corretivos } \\
\hline & \multicolumn{10}{|c|}{ Calcário dolomítico $\longrightarrow$} \\
\hline & \multicolumn{10}{|c|}{ Doses de $\mathrm{P}\left(\mathrm{mg} \mathrm{dm}^{-3}\right)$} \\
\hline & 50 & 100 & 200 & 400 & 800 & 50 & 100 & 200 & 400 & 800 \\
\hline pH em água & 6,1 & 6,3 & 6,4 & 6,3 & 6,2 & 6,4 & 6,2 & 6,3 & 5,9 & 5,9 \\
\hline P-Melich-1 (mg dm $\left.{ }^{-3}\right)$ & 11,9 & 22,3 & 45,9 & 132,4 & 247,5 & 18,9 & 22,9 & 63,4 & 148,0 & 249,6 \\
\hline $\mathrm{K}^{+}\left(\mathrm{mg} \mathrm{dm}^{-3}\right)$ & 175,0 & 187,0 & 168,0 & 200,0 & 172,0 & 218,0 & 218,0 & 212,0 & 200,0 & 184,0 \\
\hline $\mathrm{Ca}^{2+}\left(\mathrm{cmol}_{\mathrm{c}} \mathrm{dm}^{-3}\right)$ & 4,2 & 4,1 & 4,0 & 3,9 & 4,3 & 4,5 & 3,5 & 4,1 & 4,6 & 4,3 \\
\hline $\mathrm{Mg}^{2+}\left(\mathrm{cmol}_{\mathrm{c}} \mathrm{dm}^{-3}\right)$ & 1,5 & 1,4 & 1,4 & 1,4 & 1,6 & 1,3 & 1,0 & 1,3 & 1,4 & 1,5 \\
\hline $\mathrm{Al}^{3+}\left(\mathrm{cmol}_{\mathrm{c}} \mathrm{dm}^{-3}\right)$ & 0,0 & 0,0 & 0,0 & 0,0 & 0,0 & 0,0 & 0,0 & 0,0 & 0,0 & 0,0 \\
\hline $\mathrm{H}+\mathrm{Al}\left(\mathrm{cmol}_{\mathrm{c}} \mathrm{dm}^{-3}\right)$ & 2,1 & 2,1 & 2,3 & 2,6 & 2,9 & 2,1 & 2,9 & 2,3 & 2,6 & 3,2 \\
\hline $\mathrm{SB}\left(\mathrm{cmol}_{\mathrm{c}} \mathrm{dm}^{-3}\right)$ & 6,2 & 6,0 & 5,8 & 5,8 & 6,3 & 6,4 & 5,1 & 5,9 & 6,5 & 6,3 \\
\hline $\mathrm{t}\left(\mathrm{cmol}_{\mathrm{c}} \mathrm{dm}^{-3}\right)$ & 6,2 & 6,0 & 5,8 & 5,8 & 6,3 & 6,4 & 5,1 & 5,9 & 6,5 & 6,3 \\
\hline $\mathrm{T}\left(\mathrm{cmol}_{\mathrm{c}} \mathrm{dm}^{-3}\right)$ & 8,3 & 8,1 & 8,1 & 8,4 & 9,2 & 8,5 & 8,0 & 8,2 & 9,1 & 9,5 \\
\hline $\mathrm{V}(\%)$ & 74,5 & 74,0 & 71,7 & 69,1 & 68,6 & 75,2 & 63,6 & 72,1 & 71,5 & 66,2 \\
\hline m (\%) & 0,0 & 0,0 & 0,0 & 0,0 & 0,0 & 0,0 & 0,0 & 0,0 & 0,0 & 0,0 \\
\hline Matéria orgânica (\%) & 3,8 & 4,6 & 4,1 & 4,3 & 4,0 & 4,1 & 4,1 & 4,0 & 4,4 & 4,3 \\
\hline P-rem $\left(\mathrm{mg} \mathrm{L}^{-1}\right)$ & 11,2 & 11,2 & 11,2 & 11,8 & 11,8 & 10,9 & 13,6 & 12,2 & 11,5 & 15,6 \\
\hline $\mathrm{Si}\left(\mathrm{mg} \mathrm{dm}^{-3}\right)$ & 6,3 & 6,4 & 9,9 & 7,8 & 10,9 & 10,3 & 10,3 & 11,6 & 12,8 & 15,4 \\
\hline
\end{tabular}

colorimetria, enquanto, para os teores de $\mathrm{Ca}$ e $\mathrm{Mg}$, foi utilizada espectrofotometria de absorção atômica. Os teores de silício foram determinados segundo o método descrito por Korndörfer et al. (2004). O teor de proteína bruta (PB) foi quantificado de acordo com metodologias descritas por Silva (1998). Os teores de fibra em detergente neutro (FDN) e fibra em detergente ácido (FDA) foram determinados segundo técnicas descritas por Goering \& Soest (1970). A determinação da digestibilidade in vitro da matéria seca (DIVMS) foi efetuada segundo método de Tilley \& Terry (1963). Os valores encontrados foram corrigidos para matéria seca (MS), a $105^{\circ} \mathrm{C}$.

Os dados obtidos foram submetidos a análise de variância, com o auxílio do programa SISVAR (Ferreira 2008). Os efeitos dos corretivos foram comparados pelo teste $\mathrm{F}$, a 5\%, e os efeitos das doses de $\mathrm{P}$ testados por meio de equações de regressão. Os modelos de regressão foram escolhidos com base no teste $\mathrm{F}$, com significância de $1 \%$ e 5\%, e nos seus respectivos coeficientes de determinação. Para interação significativa a $5 \%$, pelo teste $\mathrm{F}$, procedeu-se ao desdobramento das doses de $\mathrm{P}$, dentro de cada corretivo.

\section{RESULTADOS E DISCUSSÃO}

Houve efeito da interação $\mathrm{P} x$ corretivos sobre o teores de $\mathrm{P}(\mathrm{p}<0,01)$ e $\mathrm{Mg}(\mathrm{p}<0,05)$ do estilosantes Mineirão (Figura 1a). Para o calcário, o teor de P, no estilosantes Mineirão, apresentou aumento no inter- valo $50-100 \mathrm{mg} \mathrm{dm}^{-3} \mathrm{de} \mathrm{P}$, com posterior redução até a dose de $400 \mathrm{mg} \mathrm{dm}^{-3}$, aumentando, novamente, até o final do intervalo estudado, e atingindo o valor máximo de $0,27 \%$ de $\mathrm{P}$ na MS, na dose de $800 \mathrm{mg} \mathrm{dm}^{-3}$ de $\mathrm{P}$ (Figura 1a).

Para o silicato, ocorreu redução no teor de $\mathrm{P}$, no intervalo $50-100 \mathrm{mg} \mathrm{dm}^{-3}$, com posterior aumento até o final do intervalo estudado, culminando com teor máximo de $0,4 \%$ de P na MS (Figura 1a).

A redução nos teores de $\mathrm{P}$, nos intervalos acima citados, possivelmente se deve ao efeito de diluição do nutriente na planta, devido a variações na resposta produtiva. Com o aumento da adubação, a resposta produtiva talvez tenha diminuído devido à menor eficiência no uso do P aplicado. Este comportamento foi mais evidente para a interação $\mathrm{P} x$ silicato, o que pode estar relacionado à maior disponibilização de P no solo, em consequência da presença do silicato.

Lopes et al. (2010) observaram que a eficiência de utilização do fósforo reduziu-se a partir da aplicação de $200 \mathrm{mg} \mathrm{dm}^{-3} \mathrm{de} \mathrm{P}$, em solos previamente corrigidos com silicato de Ca e Mg. Já para a interação $\mathrm{P}$ x calcário, a eficiência de utilização do fósforo aumentou até a dose de $400 \mathrm{mg} \mathrm{dm}^{-3} \mathrm{de} \mathrm{P}$, estabilizando-se, posteriormente.

É importante salientar que os teores de P apresentados em todos os tratamentos ficaram acima de $0,10 \%$ da MS, representando o valor crítico inferior para o estilosantes sob estádio de pré-florescimento (McIvor 1984). 

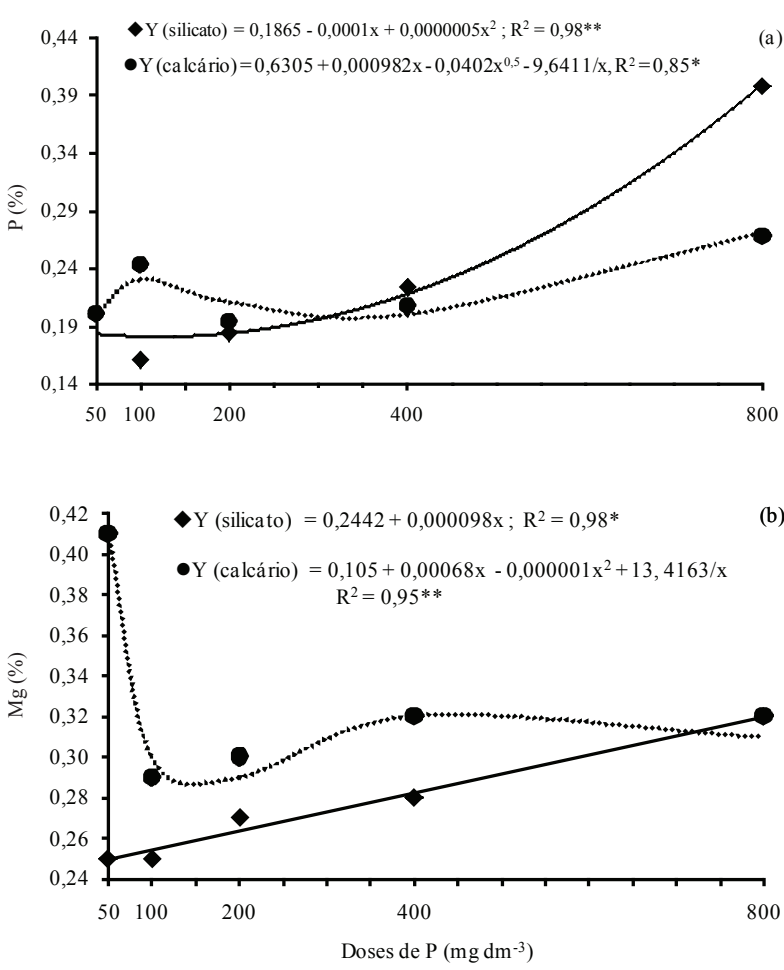

Figura 1. Teores de fósforo (a) e magnésio (b) do estilosantes Mineirão, em função do tipo de corretivo e doses de fósforo (Lavras, MG, 2007).

Para a interação $\mathrm{P}$ x silicato, os teores de $\mathrm{P}$ se mantiveram elevados (Figura 1a). Esta situação é bastante benéfica, já que os teores mínimos de $\mathrm{P}$ que uma forrageira deveria apresentar para atender às exigências de bovinos de corte em pastejo são da ordem de $0,18 \%$ da MS (Noller et al. 1996). Costa et al. (2002) também observaram teores de P superiores a $0,18 \%$ da MS, em estilosantes Mineirão com 60 dias de rebrota e adubado com $26,7 \mathrm{mg} \mathrm{dm}^{-3}$ de $\mathrm{P}$.

Nos tratamentos com aplicação de calcário, o teor de $\mathrm{Mg}$ do estilosantes Mineirão diminuiu de $0,41 \%$ para $0,29 \%$ da MS, no intervalo $50-100 \mathrm{mg} \mathrm{dm}^{-3}$ de $\mathrm{P}$, aumentando de $0,29 \%$ para $0,32 \%$ da MS, no intervalo $100-400 \mathrm{mg} \mathrm{dm}^{-3}$ de $\mathrm{P}$, com posterior tendência à estabilização (Figura 1b). Estes resultados podem ser explicados por efeitos de concentração/diluição do $\mathrm{Mg}$ no estilosantes Mineirão, devido a variações na capacidade de esta leguminosa absorver $\mathrm{Mg}$ do solo, para atender sua demanda metabólica. Apesar de o $S$. guianensis se desenvolver bem com doses relativamente baixas de $\mathrm{Mg}$ (Carvalho et al. 1988), ocorre aumento da eficiência das raízes desta leguminosa em absorver $\mathrm{Mg}$ do solo, em resposta ao incremento na adubação fosfatada
(Lopes et al. 2010), o que pode resultar em aumento da concentração deste nutriente na planta, caso não seja completamente convertido em matéria seca. Nos tratamentos com a aplicação de silicato, observou-se comportamento divergente, sendo o incremento no teor de $\mathrm{Mg}$ linear e positivo, em relação às doses crescentes de P (Figura 1). Os menores teores de $\mathrm{Mg}$ apresentados nos tratamentos que receberam silicato, em relação àqueles que receberam calcário, podem ser atribuídos ao menor teor deste nutriente no silicato de $\mathrm{Ca}$ e $\mathrm{Mg}$, em relação ao calcário dolomítico (9\% versus $14 \%$ de $\mathrm{MgO}$ ).

Todos os tratamentos apresentaram teores de Mg adequados ao desenvolvimento do estilosantes Mineirão, já que a necessidade de $\mathrm{Mg}$ para um ótimo crescimento das plantas situa-se na faixa de $0,15-0,30 \%$ da MS da parte vegetativa (Vitti et al. 2006). O teor de Mg apresentado pelo estilosantes Mineirão, em todo o intervalo estudado, também é superior às exigências míninas de todas as categorias de bovinos de corte, cuja variação é da ordem de 0,10-0,20\% da MS (NRC 1996).

$\mathrm{O}$ teor de Ca não foi influenciado por nenhum dos fatores estudados $(p>0,05)$, apresentando teor médio de $2,06 \%$ da MS. Possivelmente, a baixa mobilidade deste nutriente na planta foi o principal fator responsável por esta variável não ter sido influenciada por nenhum dos fatores estudados. Além disto, a quantidade de Ca exigida é muito variável entre espécies, com teores exigidos variando de 0,4\% até cerca de 4\% da MS das culturas (Faquin 2005). Carvalho et al. (1988) observaram elevadas repostas produtivas do $S$. guianensis, com teores de Ca na parte aérea da ordem de $1,38 \%$ da MS. Isto demonstra que os teores verificados em todos os tratamentos estão condizentes com as necessidades para o adequado desenvolvimento do estilosantes Mineirão. Os teores de $\mathrm{Ca}$ apresentados em todo o intervalo estudado, para ambos os corretivos testados, também estão bem acima das exigências mínimas de todas as categorias de bovinos de corte, que variam de $0,14 \%$ a $0,77 \%$ da MS (NRC 1996).

$\mathrm{O}$ teor de Si do estilosantes Mineirão foi influenciado pelos corretivos utilizados $(\mathrm{p}<0,05)$. A correção do solo com silicato de $\mathrm{Ca}$ e $\mathrm{Mg}$ resultou em maior teor de Si na MS do estilosantes Mineirão $(0,21 \%$ contra $0,18 \%$ de Si na MS, respectivamente, para a correção do solo com silicato e calcário). Dentre os benefícios conferidos às plantas pelo $\mathrm{Si}$ está a maior estruturação da parede celular de raízes 
e folhas. Portanto, este elemento não tem papel metabólico definido nas plantas e sua ação provoca efeitos indiretos, os quais, em conjunto, contribuem para maior produtividade vegetal (Melo et al. 2007). Estes efeitos estão relacionados à melhoria na capacidade fotossintética da planta (Agarie et al. 1998) e redução da toxidez provocada pelos elementos $\mathrm{Fe}, \mathrm{Mn} \mathrm{e}$ Al (Tisdale et al. 1993). Quanto maior a quantidade absorvida de Si pela planta, maiores poderão ser os benefícios proporcionados à mesma (Kondörfer et al. 2002), já que este é o único elemento que não causa danos às plantas, quando acumulado em grandes quantidades (Ma et al. 2001).

Houve efeito da interação doses de $\mathrm{P} x$ corretivos sobre os teores de PB $(p<0,05), \operatorname{FDN}(p<0,05)$ e FDA $(p<0,01)$ do estilosantes Mineirão (Figura 2).

Nos tratamentos com aplicação de calcário, o teor mínimo de PB do estilosantes Mineirão (15,5\%) ocorreu com a aplicação de $390 \mathrm{mg} \mathrm{dm}^{-3}$ de P. Já para a interação $\mathrm{P} x$ silicato, observou-se redução no teor de $\mathrm{PB}$, no intervalo $50-150 \mathrm{mg} \mathrm{dm}^{-3}$ de $\mathrm{P}$; elevação do teor de $\mathrm{PB}$, no intervalo $150-420 \mathrm{mg} \mathrm{dm}^{-3}$ de $\mathrm{P}$; e posterior tendência de redução do teor de $\mathrm{PB}$ (Figura 2a). A variação no teor de PB, no intervalo de adubação estudado, resulta de efeitos de diluição/ concentração do $\mathrm{N}$ biologicamente fixado, visto que nenhuma fonte mineral de $\mathrm{N}$ foi adicionada aos tratamentos. Neste caso, a fixação biológica de N (FBN) responde por $70-94 \%$ do $\mathrm{N}$ existente na parte aérea (Thomas 1995). Em todo o intervalo de adubação fosfatada, para ambos os corretivos utilizados, os teores de PB apresentados pelo estilosantes Mineirão foram superiores aos $12,6 \%$ da MS exigidos por bovinos de corte em crescimento (NRC 1996).

Ocorreu tendência de redução no teor de FDN do estilosantes Mineirão ao longo de todo o intervalo estudado, para a interação P x calcário, que, inicialmente, apresentou valor de $63,3 \%$, culminado com $55,4 \%$ na adubação com $800 \mathrm{mg} \mathrm{dm}^{-3}$ de P. Já para a interação P x silicato, o teor de FDN que, inicialmente, apresentou valor de $61,6 \%$, reduziu-se no intervalo $50-140 \mathrm{mg} \mathrm{dm}^{-3}$ de $\mathrm{P}$, apresentando valor mínimo de $52,4 \%$, elevando-se, posteriormente, a $61 \%$, com a aplicação de $800 \mathrm{mg} \mathrm{dm}^{-3}$ de P (Figura 2b). Valores de FDN da ordem de $61 \%$, para o Stylosanthes guianensis, são compatíveis com forrageiras de melhor valor nutricional, podendo, desta forma, melhorar a qualidade do alimento disponível em situações de pastagens consorciadas (Paciullo et al. 2003). O conteúdo de FDN é o melhor componente do alimento para a
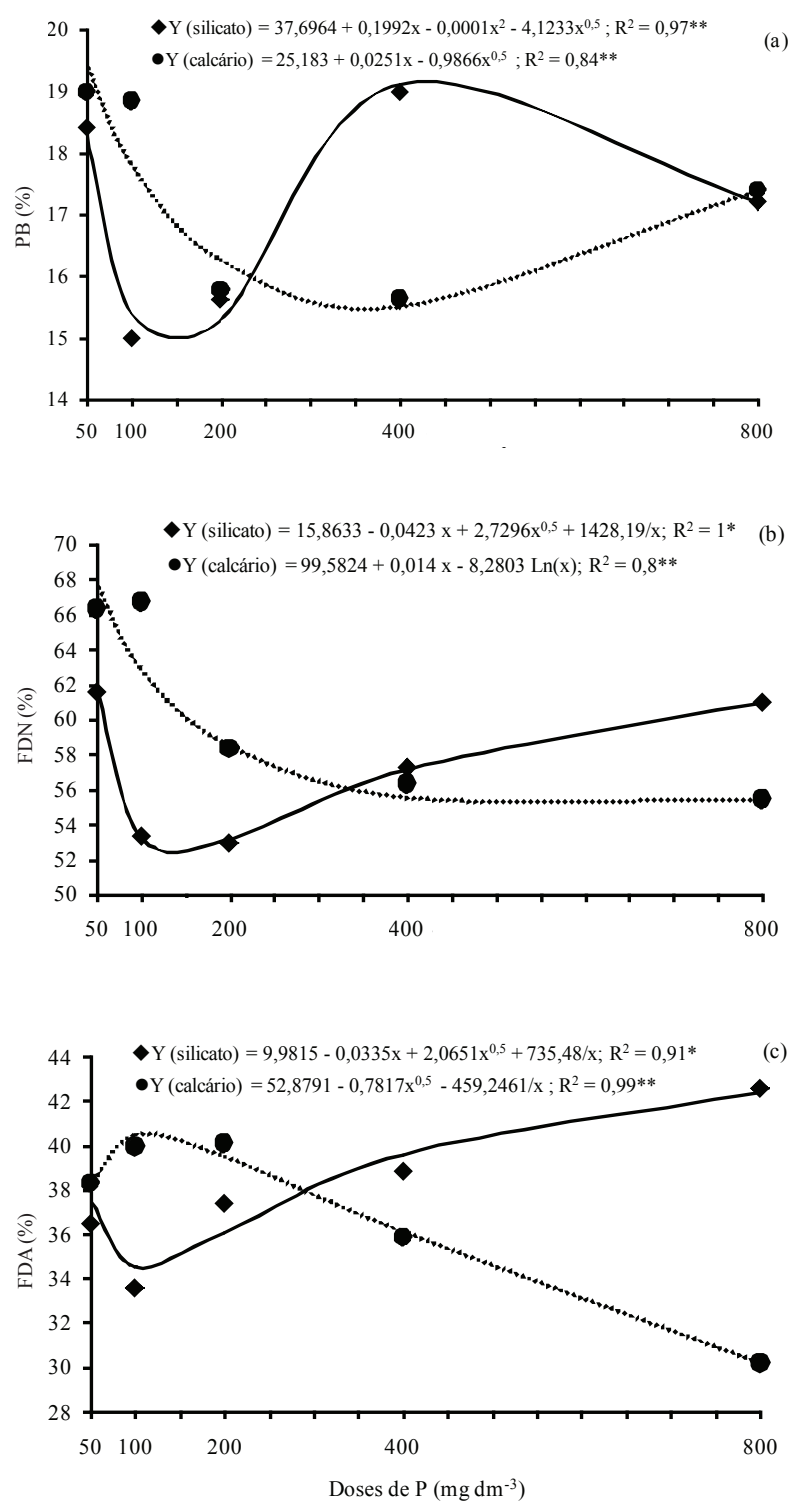

Figura 2. Teores de proteína bruta (a), fibra em detergente neutro (b) e fibra em detergente ácido (c) do estilosantes Mineirão, em função do tipo de corretivo e doses de fósforo (Lavras, MG, 2007).

predição da ingestão de matéria seca por ruminantes (Allen 2000) e, de forma geral, quanto menor o seu valor, maior é a capacidade de consumo do animal.

Para a interação P x calcário, o teor de FDA, inicialmente, elevou-se entre $50 \mathrm{mg} \mathrm{dm}^{-3}$ e $110 \mathrm{mg} \mathrm{dm}^{-3}$ de $\mathrm{P}$, apresentando valor máximo de $40,5 \%$ da $\mathrm{MS}$, reduzindo-se, no restante do intervalo, até atingir o valor mínimo de $30,2 \%$ da MS, com a aplicação de $800 \mathrm{mg} \mathrm{dm}^{-3}$ de P. Já para a interação P x silicato, $\mathrm{o}$ comportamento foi divergente, ocorrendo redução no teor de FDA, no intervalo 50-100 $\mathrm{mg} \mathrm{dm}^{-3}$ de P, 
chegando a um valor mínimo de 34,64\% da MS, com posterior aumento no restante do intervalo, atingindo valor máximo de $42,8 \%$ da MS, com a aplicação de $800 \mathrm{mg} \mathrm{dm}^{-3}$ de P (Figura 2c). É provável que este comportamento tenha ocorrido devido à presença do elemento Si, adicionado ao solo por meio do uso do silicato de $\mathrm{Ca}$ e $\mathrm{Mg}$. Juntamente com a celulose e a lignina, a sílica $\left(\mathrm{SiO}_{2} \cdot \mathrm{nH}_{2} \mathrm{O}\right)$ também é uma das frações da FDA (Soest 1982) e, desta forma, a maior disponibilidade deste elemento no solo pode contribuir para a elevação da FDA de plantas forrageiras.

Os valores observados para a interação P x silicato, em todo o intervalo, e para a interação P x calcário (Figura 2c), no intervalo 50-670 $\mathrm{mg} \mathrm{dm}^{-3}$ de $P$, são superiores aos observados por Valadares Filho et al. (2002), que relataram percentual médio de $32,0 \%$ de FDA, para o Stylosanthes guianensis. Elevado percentual de FDA é fator negativo à qualidade da forragem, reduzindo a sua digestibilidade, sendo que os nutrientes permanecem ligados à fibra e, portanto, pouco disponíveis aos animais (Moura et al. 2011).

ADIVMS não foi influenciada pelos tratamentos $(p>0,05)$. Como o Si se deposita na forma de sílica amorfa, na parede celular, seria de se esperar uma redução na DIVMS, nos tratamentos onde o silicato foi usado como corretivo, principalmente se considerarmos a alta relação do teor de FDA com a digestibilidade do alimento (Teixeira 2001). Porém, esta hipótese não se confirmou. A idade da planta, no momento do corte (68 dias), e o fato de o Mineirão ser uma leguminosa, ou seja, não pertencer a um grupo de plantas consideradas acumuladoras de $\mathrm{Si}$, podem ter sido as causas deste resultado.

A DIVMS média do estilosantes Mineirão foi de $56,7 \%$, valor inferior aos $57 \%$ observados em plantas de Stylosanthes guianensis fertilizadas com $15 \mathrm{mg} \mathrm{dm}^{-3} \mathrm{de} P$ e cortadas aos 90 dias, por Valarini \& Possenti (2006), e superior aos $54,8 \%$ observados por Lopes (2009), em estilosantes Mineirão, no início do período chuvoso. No entanto, o valor observado no presente estudo está dentro da faixa preconizada para esta leguminosa, cuja variação normal da DIVMS é de 52-60\% (Embrapa 1993).

\section{CONCLUSÃO}

A substituição do calcário por silicato de $\mathrm{Ca} \mathrm{e}$ $\mathrm{Mg}$, como corretivo de acidez do solo, não prejudicou o valor nutritivo do estilosantes Mineirão submetido a doses de fósforo.

\section{AGRADECIMENTOS}

Ao Conselho Nacional de Desenvolvimento Científico e Tecnológico (CNPq), pela bolsa de estudos e pelos auxílios concedidos.

\section{REFERÊNCIAS}

AGARIE, S. et al. Effects of silicon on transpiration and leaf conductance in rice plants (Oryza sativa L.). Plant Production Science, Tokyo, v. 1, n. 2, p. 89-95, 1998.

ALLEN, M. S. Effects of diet on short-term regulation of feed intake by lactating dairy cattle. Journal of Dairy Science, Champaign, v. 83, n. 7, p. 1598-1624, 2000.

BARCELLOS, A. O. et al. Sustentabilidade da produção animal baseada em pastagens consorciadas e no emprego de leguminosas exclusivas, na forma de banco de proteína, nos trópicos brasileiros. In: REUNIÃO DA SOCIEDADE BRASILEIRA DE ZOOTENCIA, 45., 2008, Lavras. Anais... Lavras: SBZ, 2008. p. 51-67.

CARVALHO, M. M. et al. Respostas de leguminosas forrageiras tropicais à calagem e ao fósforo, em casade-vegetação. Revista Brasileira de Ciência do Solo, Campinas, v. 12, n. 2, p. 153-159, 1988.

COSTA, K. A. P. et al. Avaliação do desenvolvimento e absorção de nutrientes pelo Stylosanthes guianensis cv. Mineirão sob doses crescentes de calcário em solo do Cerrado. Ciência Animal Brasileira, Goiânia, v. 3, n. 2, p. 13-19, 2002.

EMPRESA BRASILEIRA DE PESQUISA AGROPECUÁRIA (Embrapa). Centro Nacional de Pesquisa de Solos. Sistema brasileiro de classificação de solos. 2. ed. Rio de Janeiro: Embrapa, 2006.

EMPRESA BRASILEIRA DE PESQUISA AGROPECUÁRIA. Centro Nacional de Pesquisa dos Cerrados. Recomendações para estabelecimento e utilização do Stylosanthes guianensis cv. Mineirão. Planaltina: Embrapa Cerrados, 1993. (Comunicado técnico, 49).

FAQUIN, V. Nutrição mineral de plantas. Lavras: UFLa/ Faepe, 2005.

FERREIRA, D. F. SISVAR: um programa para análises e ensino de estatística. Revista Symposium, Lavras, v. 6, n. 2, p. 36-41, 2008.

FORTES, C. A. et al. Níveis de silicato de cálcio e magnésio na produção das gramíneas Marandu e Tanzânia cultivadas em um Neossolo Quartzarênico. Ciência e Agrotecnologia, Lavras, v. 32, n. 1, p. 267-274, 2008. 
GIBSON, A. H. Limitation to nitrogen fixation in legumes. In: NEWTON, W. E.; NYMAN, O. J. (Eds.). Proceedings of the international symposium of nitrogen fixation. Washington, DC: University Press, 1976. p. 400-428.

GOERING, H. K.; SOEST, P. J. V. Forage fiber analysis: apparatus reagents, procedures and some applications. Washington, DC: USDA, 1970.

KORNDÖRFER, G. H.; PEREIRA, H. S.; CAMARGO, M. S. Silicatos de Ca e Mg na agricultura. Uberlândia: UFU/ICIAG, 2002.

KORNDÖRFER, G. H.; PEREIRA, H. S.; NOLLA, A. Análise de Si no solo, planta e fertilizantes. Uberlândia: UFU/ICIAG, 2004.

LEITE, P. C. Interação silício-fósforo em Latossolo Roxo cultivado com sorgo em casa-de-vegetação. $1997.84 \mathrm{f}$. Tese (Doutorado em Agronomia)-Universidade Federal de Viçosa, Viçosa, 1997.

LOPES, J. Doses de fósforo e taxas de lotação em pastagem de capim-xaraés consorciado com estilosantes Mineirão. 2009. 139 f. Tese (Doutorado em Zootecnia)Universidade Federal de Lavras, Lavras, 2009.

LOPES, J. et al. Calagem, silicatagem e doses de fósforo no crescimento e nutrição mineral de estilosantes. Pesquisa Agropecuária Tropical, Goiânia, v. 40, n. 2, p. 150-158, 2010.

LOPES, J. et al. Nodulação e produção de raízes do estilosantes Mineirão sob efeito de calagem, silicatagem e doses de fósforo. Ciência e Agrotecnologia, Lavras, v. 35, n. 1, p. 99-107, 2011.

MA, J. F.; MIYAKE. Y.; TAKAHASHI, E. Silicon as a beneficial element for crop plants. In: DATNOFF, L. E.; SNYDER, G. H.; KORNDÖRFER, G. H. Silicon in agriculture. Amsterdam: Elsevier, 2001. p. 17-39.

McIVOR, J. G. Phosphorus requirements and responses of tropical pasture species: native and introduced grasses, and introduced legumes. Australian Journal of Experimental Agriculture Animal Husbandry, Melbourne, v. 24, n. 8, p. 370-378, 1984.

MELO, S. P.; MONTEIRO, F. A.; MANFREDINI, D. Silicate and phosphate combinations for Marandu palisade grass growing on an Oxisol. Scientia Agricola, Piracicaba, v. 64, n. 3, p. 275-281, 2007.

MOURA, R. L. et al. Razão folha/haste e composição bromatológica da rebrota de estilosantes Campo Grande em cinco idades de corte. Acta Scientiarum, Maringá, v. 33, n. 3, p. 249-254, 2011.

NATIONAL RESEARCH COUNCIL (NRC). Nutrients requeriments of beef cattle. 7. ed. Washington, D.C.: The National Academies Press, 1996.
NOLLER, C.H.; NASCIMENTO JÚNIOR, D.; QUEIROZ, D. S. Exigências nutricionais de animais em pastejo. In: SIMPÓSIO SOBRE MANEJO DA PASTAGEM, 13., 1996, Piracicaba. Anais... Piracicaba: Fundação de Estudos Agrários “Luiz de Queiroz”, 1996. p. 319-352.

PACIULLO, D. S. C. et al. Características produtivas e qualitativas de pastagem de braquiária em monocultivo e consorciada com estilosantes. Pesquisa Agropecuária Brasileira, Brasília, DF, v. 38, n. 3, p. 421-426, 2003.

PEREIRA, J. M. Leguminosas forrageiras em sistemas de produção de ruminantes: onde estamos? Para onde vamos? In: SIMPÓSIO SOBRE MANEJO ESTRATÉGICO DE PASTAGENS, 1., 2002, Viçosa. Anais... Viçosa: Simfor, 2002. p. 109-147.

SANTOS, I. P. A. et al. Influência do fósforo, micorríza e nitrogênio no conteúdo de minerais de Brachiaria brizantha e Arachis pintoi consorciados. Revista Brasileira de Zootecnia, Viçosa, v. 31, n. 2, p. 605-616, 2002.

SARRUGE, J. R.; HAAG, H. P. Análise química em plantas. Piracicaba: ESALQ, 1974.

SILVA, D. J. Análise de alimentos: métodos químicos e biológicos. Viçosa: UFV, 1998.

SOEST, P. J. V. Nutritional ecology of the ruminants. Corvallis: O \& Books, 1982.

THOMAS, R. J. Role of legumes in providing $\mathrm{N}$ for sustainable tropical pasture systems. Plant and Soil, Dordrecht, v. 174, n. 1-2, p. 103-118, 1995.

TEIXEIRA, J. C. Nutrição de ruminantes. Lavras: UFLa/ Faepe, 2001.

TILLEY, J. A. M.; TERRY, R. A. A two-stage technique for the "in vitro" digestion of forage crops. Journal of the British Grassland Society, Oxford, v. 18, n. 2, p. 104-111, 1963.

TISDALE, S. L.; NELSON, W. J.; BEATON, J. D. Soil fertility and fertilizers. New York: Macmillan Publishing Company, 1993.

VALADARES FILHO, S. C.; ROCHA JÚNIOR, V. R.; CAPPELLE, E. R. Tabelas brasileiras de composição de alimentos para bovinos. Viçosa: UFV, 2002.

VALARINI, M. J.; POSSENTI, R. A. Nutritive value of a range of tropical forage legumes. Tropical Grasslands, Brisbane, v. 40, n. 1, p. 183-187, 2006.

VITTI, G. C.; LIMA, E.; CICARONE, F. Ca, Mg e enxofre. In: FERNANDES, M. S. (Ed.). Nutrição mineral de plantas. Viçosa: SBCS, 2006. p. 299-325. 